\title{
Evaluation of Strain Hardening Exponent through Indentation Size Effect (ISE) of Vickers Hardness
}

\author{
I N Budiarsa ${ }^{\# 1}$, NL Watiniasih ${ }^{* 2}$, I N Gde Antara ${ }^{\# 3}$ \\ \#Mechanical Engineering. Udayana University. Badung 80361 Bali Indonesia \\ ${ }^{1}$ nyoman.budiarsa@unud.ac.id \\ 3 antara@unud.ac.id \\ ${ }^{*}$ Faculty of Mathematics and Natural Sciences. Udayana University. Badung 80361 Bali Indonesia \\ ${ }^{2}$ luhwatiniasih@unud.ac.id
}

\begin{abstract}
Another ways to prediction the force-displacement curve of indentation (P-h curves) from constitutive material properties has been created and assessed for Vickers Indentation. This gave a helpful apparatus to assess the possibility of utilizing hardness value in anticipating the constitutive material parameters concerning precision and uniqueness by mapping through every potential material reaches. The scale of Indentation Size Effect (ISE) can be reliably estimated and it can possibly be connected to the Hardness-to-Modulus proportion $(\mathrm{H} / \mathrm{E})$. The size of ISE of the examples tried is genuinely repeatable and the connection with material properties (e.g $\mathrm{H} / \mathrm{E})$ is significant and reliable. Idea to utilize the space size information of the Vickers indentation has been investigated to improve the accuracy/robustness of inverse properties modelling dependent on hardness utilizing steel as material framework. The work demonstrated that there is huge ISE in the Vickers hardness tests and the scale and consistency /unwavering quality of ISE was investigated by fitting information observing the Meyer's Power Law and the proportional specimen resistance (PSR) models. The ISE power law index displayed a sensible concurrence with the hardness-elastic modulus ratio (H/E). Another idea of utilizing ISE data for assessing the Strain hardening exponent (n) estimations of steel has been investigated and indicated sensible outcomes for narrowing the scope of anticipated material properties dependent on hardness value
\end{abstract}

Keyword - Strain hardening exponent (n); Vickers hardness value (HV); yield stress $(\sigma y)$

\section{INTRODUCTION}

In a hardness measurement (such as Vickers, Knoop and HB), the impression size was estimated after the applied load has been discharged. Hypothetically, the hardness of the materials should be similar when utilizing diverse applied load, how now and again, the hardness has been seen as reliant on the heap applied [1]. This was defined as indentation size effect (in some cases, it was also defined as indentation load effect).The indentation size effect (ISE) in metals is described as an increase in hardness with a decrease in indentation depth and contrary to conventional plasticity behaviour. This phenomena has been reported in a wide range of materials including metals [2], [3], [4], ceramics [5], Glasses [6], polymers [7]. There is another type of ISE called reverse ISE[8], This case has been found primarily in ceramics and single crystal materials [9], [10]. The source of ISE is still a subject of study, which has been ascribed to various phenomena and mechanism including: elastic recovery, work hardening during indentation and strain gradients related with dislocations [11], [12]

The most widely recognized indentation size effect is presumably the errors related with the area function of the indenter, especially at very small values of penetration depth. In any case, regardless of whether these impacts are limited, it is still commonly saw that for certain materials, for example crystalline solids, that are ostensibly isotropic, an indentation size effect is still observed[8]. In light of the geometric necessary dislocations (GNDs) model, the impact of an expansion separation thickness because of additional hardening will influence the length and volume of dislocation stored [9], [10], [11]. This conceivably could give extra arrangement of exploratory information mirroring the materials properties. Be that as it may, regardless of its wide use, the materials behaviour (represented by the hardness or P-h curves) are not expressly connected with the constitutive material properties (yielding stress, strain hardening exponent). Further work is required to have the option to predict indentation resistance (P-h Curves as well as ISE) from constitutive materials parameters. On the opposite side, it is additionally of extraordinary criticalness to both research and down to earth use to investigate the possibility to utilize ISE data to foresee the constitutive materials properties particularly Strain hardening exponent. It might conceivably give a quicker method to material parameter identification and relevant in circumstances where standard specimens are not accessible (for example small samples and complex structures). Improvements of the two regions require a nitty gritty comprehension program connecting constitutive materials properties, P-h curve and Indentation Size Effect (ISE) of Vickers Hardness. In this work, 
the ISE of steels with chosen heat treatments (annealed or tempered) has been examined and dissected. Deliberately hardness tests were performed inside a commonly used micro-load range. The trial information was investigated by the Meyer power-law and the PSR models and the connection between ISE to material properties is investigate

\section{EXPERIMENTAL METHODS.}

Material utilized in the ISE study were Carbon steel with different arrangements of carbon content (Carbon steel with carbon content $0.10 \% \mathrm{C}, 0.54 \% \mathrm{C}$ and $0.85 \% \mathrm{C})$ and Mild steel. One of the examples $(0.54 \%$ carbon $)$ was prepared through different heat treatments (annealing, quenching and tempering) The sample was normalized at $840^{\circ} \mathrm{C}$, then annealed, quenched and tempered at $\mathrm{T}=400^{\circ} \mathrm{C}$ and $\mathrm{T}=600^{\circ} \mathrm{C}$. The Vickers hardness tests were done utilizing a Duramin-1 Struers Vickers hardness tester. The Duramin-1 Struers Vickers hardness tester utilizes a direct load method with a load range of $490.3 \mathrm{mN}$ to $19.61 \mathrm{~N}$. The indenter has the type of right pyramid with a square base and an edge of $136^{\circ}$ between inverse face. So as to decide the effect of the indentation load, a range of loads was tried. This will viably produce material samples with various hardness-tomodulus $(\mathrm{H} / \mathrm{E})$ proportions as the Young's modulus of steel doesn't essentially with the heat treatments.

\section{INDENTATION SIZE EFFECT (ISE) OF ViCKERS HARDNESS IN STEEL.}

The hardness data with various applied loads of the steels with various conditions is appeared in Figure 1 . The data shows that hardness expanded with expanding carbon content in the steels. The sample with various heat-treatments demonstrated that the hardness diminished with annealing and tempering temperature. In all cases, there is an unmistakable indentation size effects and the degree of hardness decline with applied load is distinctive among the material.

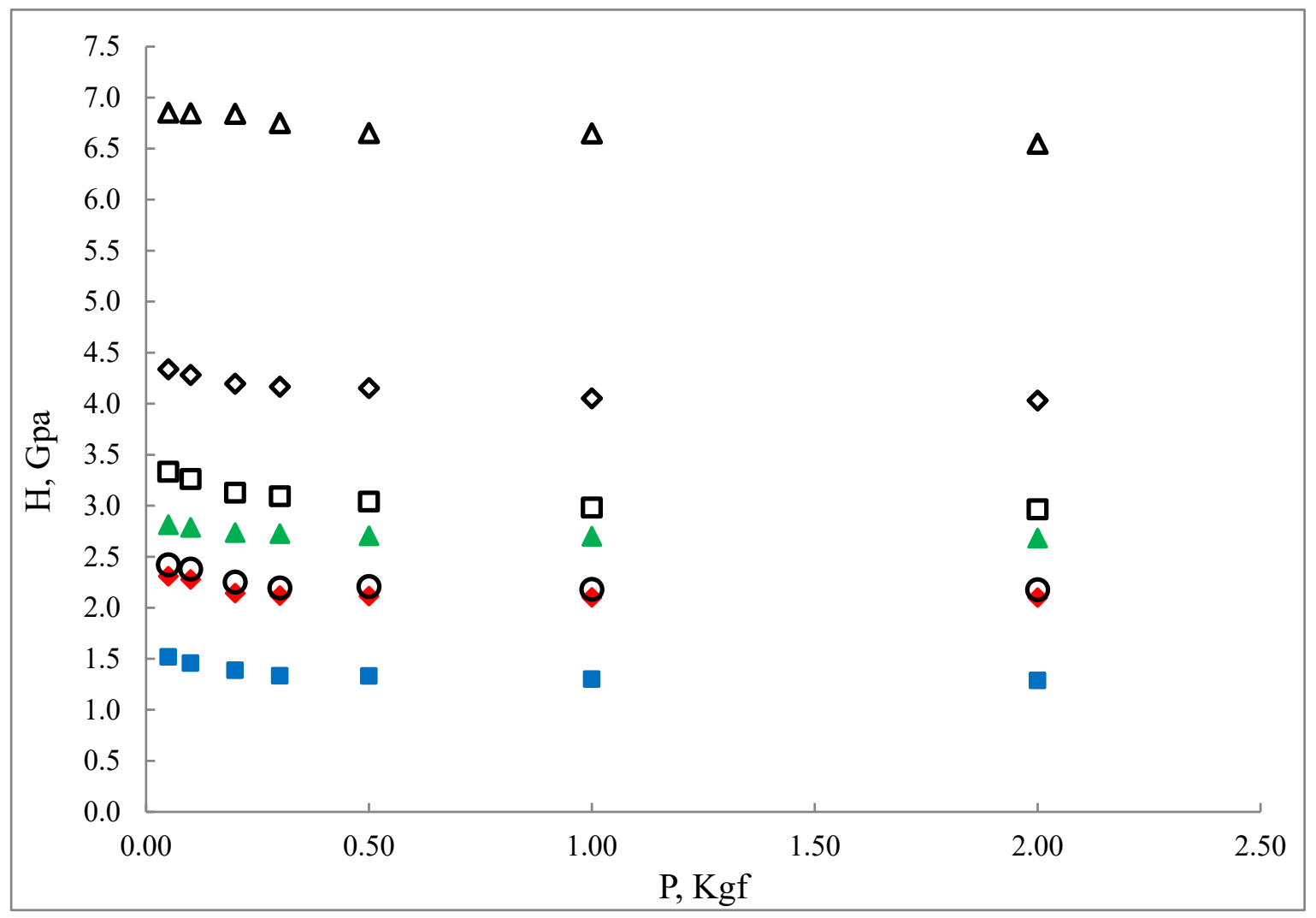

Figure 1 Typical results of hardness measurements of carbon steels with different carbon content and heat treatments conditions. Blue squares denote samples material of carbon steel with $0.1 \%$ of carbon, red diamond denote carbon steel with $0.54 \%$ of carbon, green triangles denote carbon steel with $0.85 \%$ of carbon, hollow circles denote carbon steel with $0.54 \%$ of carbon with Quenching in $840^{\circ} \mathrm{C}$ then continued with annealing, hollow squares denote carbon steel with $0.54 \%$ carbon with Quenching in $840^{\circ} \mathrm{C}$ then continue heated in $600^{\circ} \mathrm{C}$, hollow diamond denote carbon steel with $0.54 \%$ of carbon with Quenching in $840^{\circ} \mathrm{C}$ then continue heated in $400^{\circ} \mathrm{C}$, hollow triangles denote carbon steel with $0.54 \%$ of carbon with Quenching in $840^{\circ} \mathrm{C}$ then continue heated in $200^{\circ} \mathrm{C}$. 
The ISE has generally been portrayed regarding the Meyer power law and the proportional specimen resistance (PSR) model [5],[14]. The force law depicted connections between the applied load (P), and the resulting indentation size $(\mathrm{d})$ :

where $\mathrm{P}$ is the applied load, $\mathrm{d}$ is the corner to corner length and, $\mathrm{A}$ and $\mathrm{n}$ are constants. The exponent $\mathrm{n}$, the Meyers exponent is a proportion of the ISE conduct, which has been experimentally observed in the range of 1.5 and 2.0[5], When $\mathrm{n}>2$, there is reverse ISE conduct, while when $\mathrm{n}=2$, the hardness is independent of the applied test load, and is given by Kick's law. Where Ai is geometric change factor for the indenter utilized. Eq.1 is utilized to examine the relationship among load and indentation size and determine Meyers exponent (n). The incline, which represents the ISE index n, was higher for the tempered condition than the strengthened condition and showed an expanding pattern with expanding tempering temperature demonstrating less critical ISE over the load range utilized. This proposed ISE expanded with expanding nominal hardness values. Proportional specimen resistance (PSR) approaches brought about a connection between the applied load (P) and the subsequent indentation size $\mathrm{d}(\mu \mathrm{m})$ with which, the normal ISE conduct could be portrayed by the relation [5]

$F=a_{1} d^{1}+a_{2} d$

Where the parameter $\mathrm{a}_{1}$ portrays the load dependence of hardness and $\mathrm{a}_{2}$ is a load-independent constant, while $a_{1} \mathrm{~d}^{1}$ : The vitality consumed in making new surface (Specimen surface energy). $\mathrm{a}_{2} \mathrm{~d}^{2}$ : The work of permanent deformation or the volume vitality of deformation [8]. Equation (2) could be utilized to portray the measured data as delineated in Fig.2. The relationship coefficients were again more prominent than 0.99 in all cases. There was an away from between the incline of data for the annealed condition and the tempered conditions, which expanded as the hardness of the samples expanded. The hardness test results indicated that in every one of the cases, there was a reasonable ISE in the steel tests tried. Both force law and PSR model could precisely delineate the ISE observed. Figure 3 portrays the power-law index ' $n$ ' against the hardness-to-modulus ratio $\mathrm{H} / \mathrm{E}$. It is obviously indicated that the ISE parameters showed a sensible concurrence with the H/E values This recommends, like the Knoop hardness in single crystals of ceramics [9], [10] ISE could be linked to the hardness-Elastic modulus.

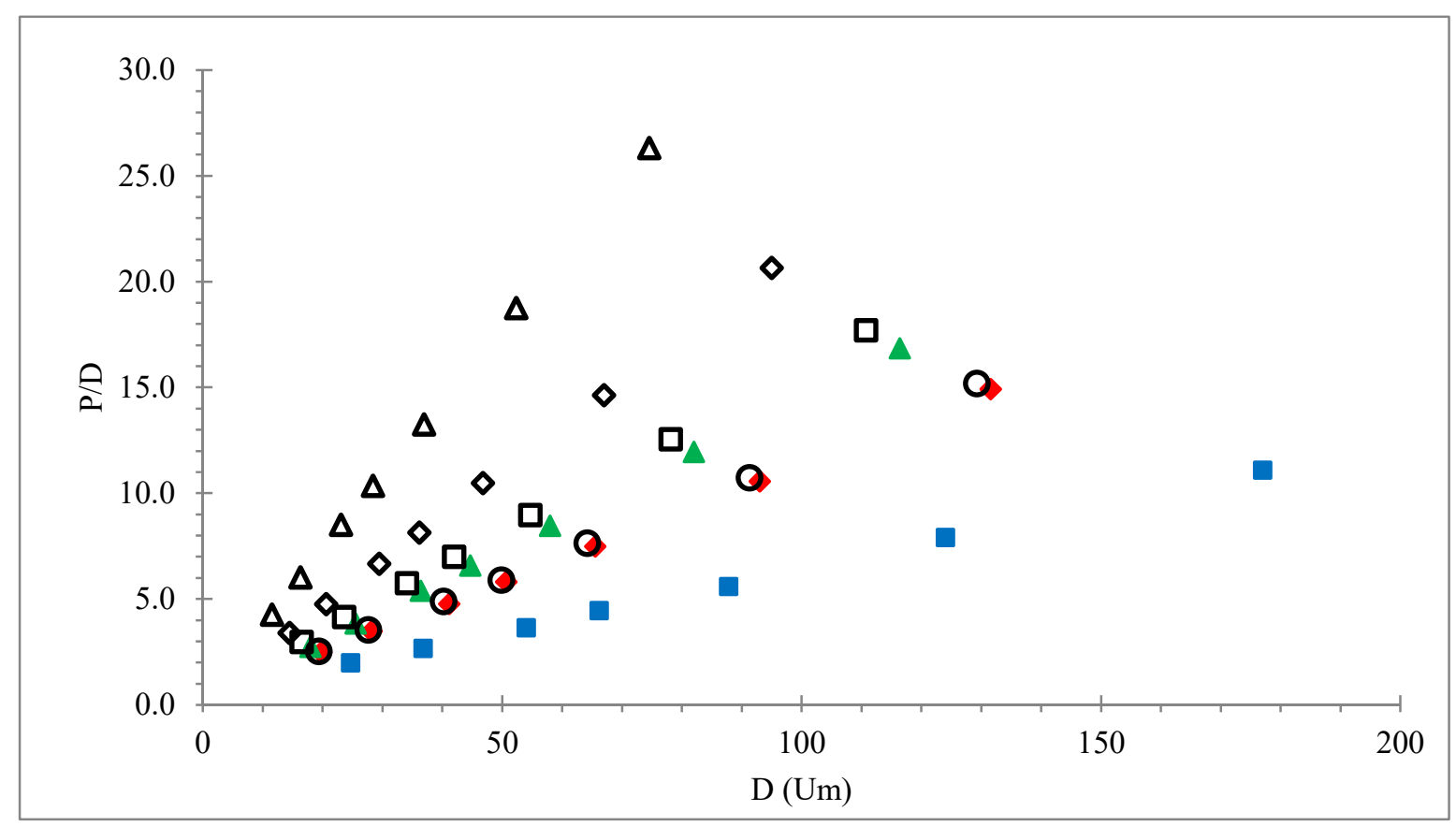

Figure 2 Indentation data for metallic metal with different carbon contents and heat treatments plotted according to the PSR model. P is the applied load and D is the diagonal length. Blue squares denote samples material of carbon steel with $0.1 \%$ of carbon, red diamond denote carbon steel with $0.54 \%$ of carbon, green triangles denote carbon steel with $0.85 \%$ of carbon, hollow circles denote carbon steel with $0.54 \%$ of carbon with Quenching in $840^{\circ} \mathrm{C}$ then continued with annealing, hollow squares denote carbon steel with $0.54 \%$ carbon with Quenching in $840^{\circ} \mathrm{C}$ then continue heated in $600^{\circ} \mathrm{C}$, hollow diamond denote carbon steel with $0.54 \%$ of carbon with Quenching in $840^{\circ} \mathrm{C}$ then continue heated in $400^{\circ} \mathrm{C}$, hollow triangles denote carbon steel with $0.54 \%$ of carbon with Quenching in $840^{\circ} \mathrm{C}$ then continue heated in $200^{\circ} \mathrm{C}$. 
Similar approach has been extended to establishing the correlation between the ISE parameter with $\mathrm{H} / \mathrm{E}$ following the Proportional specimen resistance (PSR) parameters (a1 and a2). The data is shown in Figure 4 together with some published data from other sources. In both case, there is a clear link between the ISE parameters (a1 and a2) with the H/E ratio. The data clear showed that materials with higher hardness-elastic modulus $(\mathrm{H} / \mathrm{E})$ have more significant ISE.

To certain extent, $\mathrm{H} / \mathrm{E}$ represents the relative contributions of plastic and elastic deformation associated with a particular indentation, this implies that the ISE is associated with dislocation movement possibly Strain hardening behaviour. This potentially could provide a method to normalize ISE in order to quantify the scale of ISE. If ISE can be correlated to the $\mathrm{H} / \mathrm{E}$, then potentially it can be used as a measure input for inverse property estimation. In order to determine the effect of the indentation load, a range of loads was tested. Figure 5 shows the hardness values with different loads, two materials in comparison with the original measured hardness values with different loads. The predicted Vickers hardness (Hv) showed a similar level of agreement with the experimental data. In the case of the $0.1 \mathrm{C}$ Steel, the hardness values $(\mathrm{Hv})$ is within $98.368 \%$, while Mild steel is within $98.611 \%$ of the measured value. As shown in the figure.

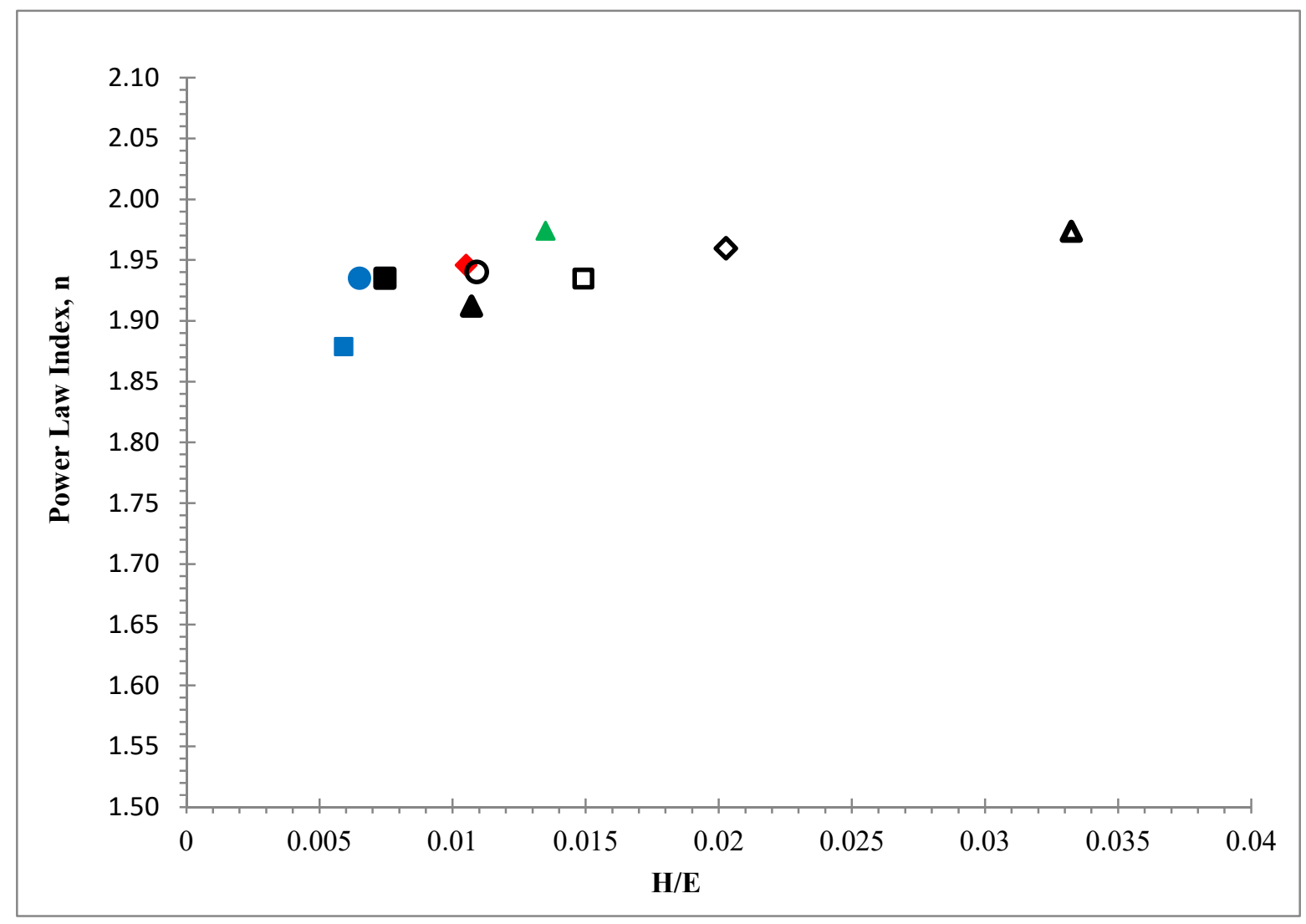

Figure 3 Correlation of power-law index $n$ with the hardness-to-modulus ratio H/E for steels. Blue squares denote samples material of carbon steel with $0.1 \%$ of carbon (A), red diamond denote carbon steel with $0.54 \%$ of carbon, green triangles denote carbon steel with $0.85 \%$ of carbon, hollow circles denote carbon steel with $0.54 \%$ of carbon with Quenching in $840^{\circ} \mathrm{C}$ then continued with annealing, hollow squares denote carbon steel with $0.54 \%$ carbon with Quenching in $840^{\circ} \mathrm{C}$ then continue heated in $600^{\circ} \mathrm{C}$, hollow diamond denote carbon steel with $0.54 \%$ of carbon with Quenching in $840^{\circ} \mathrm{C}$ then continue heated in $400^{\circ} \mathrm{C}$, hollow triangles denote carbon steel with $0.54 \%$ of carbon with Quenching in $840^{\circ} \mathrm{C}$ then continue heated in $200^{\circ} \mathrm{C}$, blue circles denote carbon steel with $0.1 \%$ of carbon (B), black triangles denote mild steel and the black squares denote Toasen specimen

The hardness of the $0.1 \% \mathrm{C}$ steel is a lot of lower than that of the mild steel samples. In the two cases, inside the testing load utilized, the data plainly demonstrated that expanding the applied load brought about a diminishing of the hardness values. As the load expanded, the varieties of hardness regarding load turned out to be less noteworthy. Similar of Indentation size effect (ISE) trend has also been found with other carbon steels of different conditions. It is clearly shown that predicted hardness value is in a good agreement with the Vickers hardness at higher loads, where there is no indentation size effect (ISE). This proves that the approach is a valid approach to estimate the non-ISE Vickers hardness values. The fundamental mechanisms of ISE are still not entirely clear but this result clearly suggest that any direct hardness analysis and inverse property prediction 
should be based non-ISE data. This proved that the program established can be used to link continuous indentation P-h curves and the hardness values, which can then be used as a tool to map Hv values over a wide range of materials to establish the link between $\mathrm{Hv}$ and the representative stress (or)

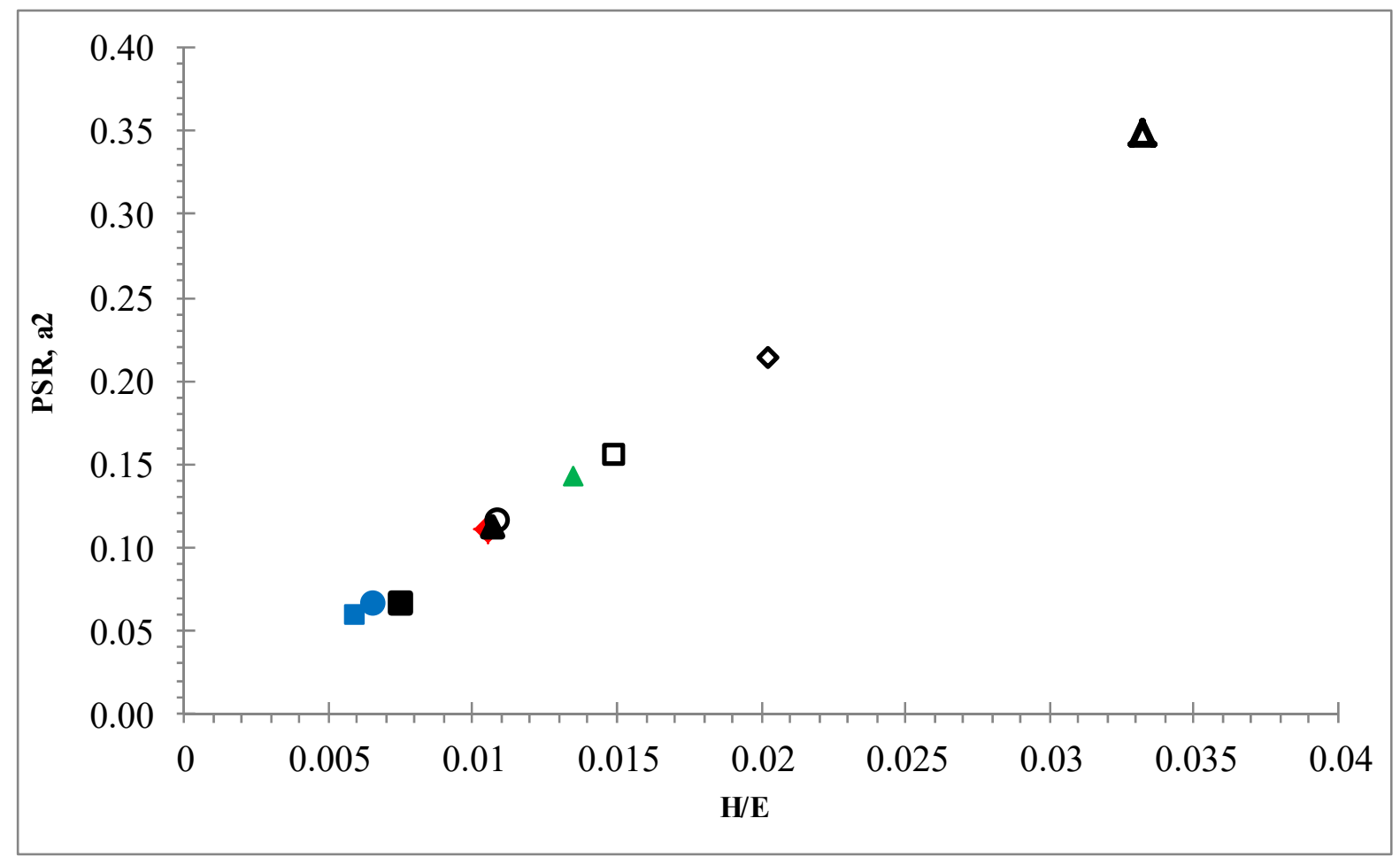

Figure 4 The relationship between the parameters a1 and a2 with ratio $(\mathrm{H} / \mathrm{E})$. Blue squares denote samples material of carbon steel with $0.1 \%$ of carbon (A), red diamond denote carbon steel with $0.54 \%$ of carbon, green triangles denote carbon steel with $0.85 \%$ of carbon, hollow circles denote carbon steel with $0.54 \%$ of carbon with Quenching in $840^{\circ} \mathrm{C}$ then continued with annealing, hollow squares denote carbon steel with $0.54 \%$ carbon with Quenching in $840^{\circ} \mathrm{C}$ then continue heated in $600^{\circ} \mathrm{C}$, hollow diamond denote carbon steel with $0.54 \%$ of carbon with Quenching in $840^{\circ} \mathrm{C}$ then continue heated in $400^{\circ} \mathrm{C}$, hollow triangles denote carbon steel with $0.54 \%$ of carbon with Quenching in $840^{\circ} \mathrm{C}$ then continue heated in $200^{\circ} \mathrm{C}$, blue circles denote carbon steel with $0.1 \%$ of carbon (B), black triangles denote mild steel and the black squares denote Toasen specimen

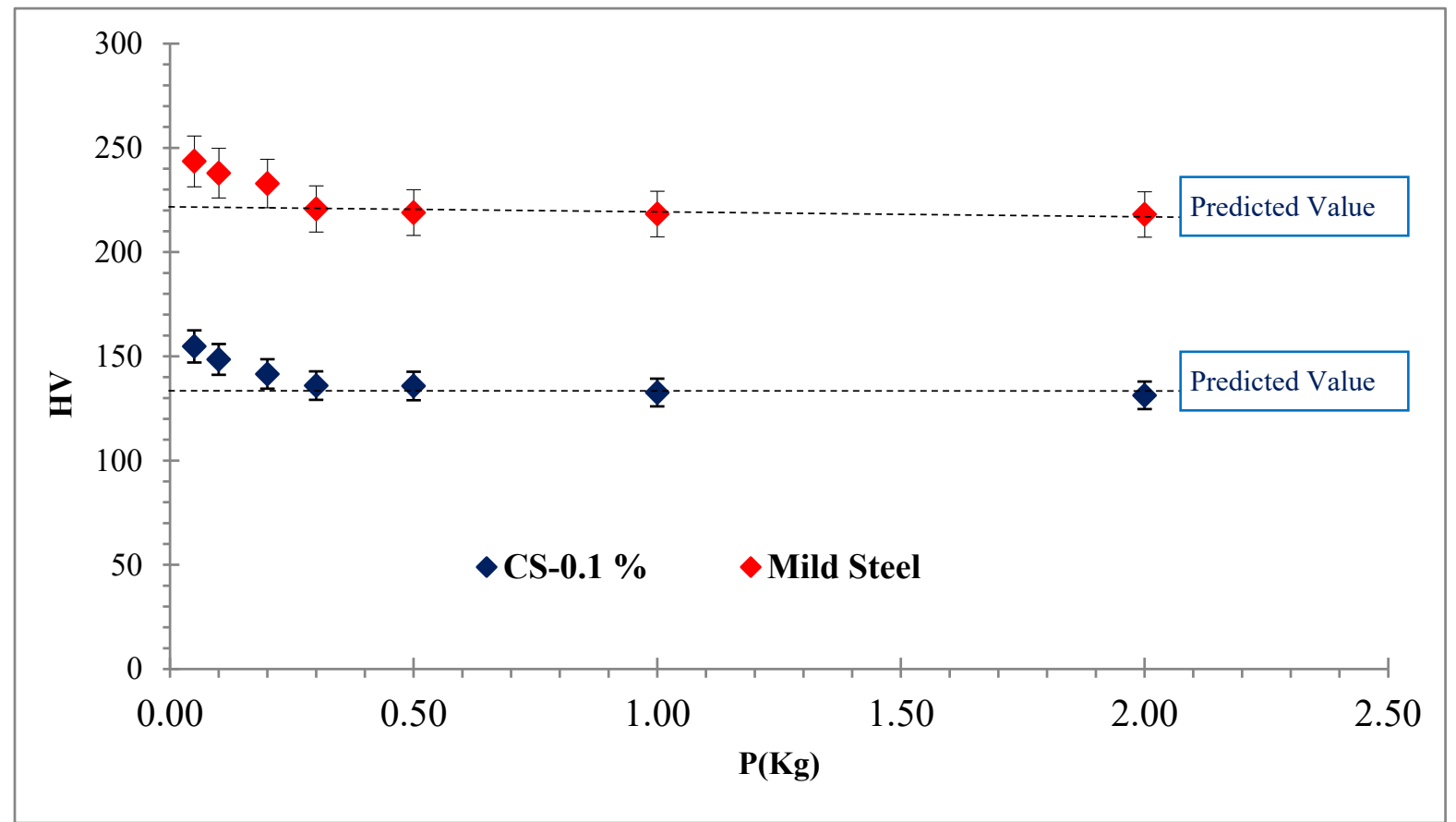


Figure 5 Comparison between predicted Vickers hardness values and the experimental data, with the non-ISE hardness data. red diamond denote samples material of carbon steel with $0.1 \%$ of carbon. While blue diamond denote samples material of mild steel. showing the predicted $\mathrm{Hv}$ is in good agreement

Similar of Indentation size effect (ISE) trend has also been found with other carbon steels of different conditions. It is clearly shown that predicted hardness value is in a good agreement with the Vickers hardness at higher loads, where there is no indentation size effect (ISE). This proves that the approach is a valid approach to estimate the non-ISE Vickers hardness values. The fundamental mechanisms of ISE are still not entirely clear but this result clearly suggest that any direct hardness analysis and inverse property prediction should be based non-ISE data. This proved that the program established can be used to link continuous indentation P-h curves and the hardness values, which can then be used as a tool to map $\mathrm{Hv}$ values over a wide range of materials to establish the link between $\mathrm{Hv}$ and the representative stress ( $\sigma \mathrm{r})$

\section{ISE APPROACH In DETERMINING The STRAIn HARDENING EXPONENT.}

The extent of ISE can be consistently measured and it can potentially be linked to the H/E ratio. The scale of ISE of the samples tested is fairly repeatable and the link with material properties (e.g H/E) is significant and reliable. This potentially could provide additional set of experimental data reflecting the materials properties. The fundamental reason for ISE is not conclusive, however, a commonly accepted concept (also proved by the link of ISE with $\mathrm{H} / \mathrm{E}$ ) is that it is associated with the gradient strain and dislocation density during the indentation process. Based on the geometric necessary dislocations (GNDs) model, the influence of an increase dislocation density due to additional hardening will affect the length and volume of dislocation stored [9], [11], [13]. Recently, Kim et al., has evaluated the feasibility of estimating plastic flow properties by characterizing indentation size effect using a sharp (Berkovich) indenter based on nano-indentation data and resulted showed some success based on the P-h curves [15], [16], [17] This can potentially be used with the aid of the P-h curve prediction method developed in this work to estimate the range of constitutive material properties, in particular the Strain hardening exponent. This can further improve the accuracy of the inverse FE modelling process. The process and key concepts is outlined below. Based on the strain gradient (MSG) plasticity model, in theory, the non ISE hardness and the ISE hardness can be expressed by following equation [18]

$$
\frac{\mathrm{H}}{\mathrm{H}_{\mathrm{o}}}=\sqrt{1+\frac{\mathrm{h}^{*}}{\mathrm{~h}}}
$$

Where $\mathrm{H}$ is the hardness, Ho is the macroscopic hardness and ' $\mathrm{h}$ ' is the indentation depth, while $\mathrm{h} *$ is a length which characterizes the depth dependence of the hardness.

$$
\mathrm{h}^{*}=\mathrm{h} *\left(\left(\frac{\mathrm{MI}}{\mathrm{H}_{\mathrm{\varepsilon}}}\right)^{2}-1\right)
$$

By defined the representative stress and strain for the deformation state of the material underneath the sharp indenter, the representative stress $\sigma \boldsymbol{r}$ and $\boldsymbol{\varepsilon}_{\mathbf{r}}$ the corresponding the representative stress such that[19]

$$
\sigma_{r}=\mathrm{K} \varepsilon_{\mathrm{p}}{ }^{\mathrm{n}}
$$

Where $\varepsilon_{\mathrm{r}}$ is the representative strain, $\mathrm{n}$ is Strain hardening exponent. Kim's work showed the Strain hardening exponent (n) was found to following this equation [20]

$$
\mathrm{n}=-\frac{1}{2 \ln \Omega_{\mathrm{r}}} \ln \left(\frac{\mathrm{h}}{\mathrm{b}}\right)-\frac{1}{\ln \mathrm{s}_{\mathrm{r}}} \ln \left(\frac{\mathrm{K}}{\mathrm{z}}\right)+\frac{1}{\ln \mathrm{s}_{\mathrm{r}}} \ln \left(\frac{8}{\sqrt{2}} \alpha \cot \theta\right)
$$

Where $\mathrm{n}$ is the work hardening coefficient $\mathrm{b}$ is the Berger vector, $\mathrm{K}$ is strength constant, $\mu$ is the shear modulus, $\alpha$ is a contact between 0.3-0.6. The $h^{*}$ and $h$ can be estimated from the hardness values at different loads. In this work, $\mathrm{h}^{*}$ can be estimated from the impression size (a); K value can be calculated from the stress strain curve of the materials. The Strain hardening exponent (n) modulus (for steel $\mu=79.3 \mathrm{GPa}$ ), $\varepsilon \mathrm{r}$ is representative strain. In this work use $\varepsilon r=0.029$, length $h^{*}$ can be determine from the hardness values at different loads. where $\mathrm{H}$ is hardness and $\mathrm{H}_{\mathrm{o}}$ hardness on the non-ISE. The indentation depth (h) can be estimated from the impression size. $\alpha$ is a constant with value from $0.3-0.6$. and $\theta$ is indenter geometry $\left(\theta\right.$ for Vickers indenter is $\left.68^{\circ}\right)$. When the material parameters, $\mathrm{b}, \mathrm{K}, \mu$, and $\alpha$, and the indenter geometry $\theta$ are known Strain hardening exponent (n) by using Eq. (6) can be determined. By using this range, the Strain hardening exponent of the two materials (Figure 5 ) has been calculated/estimated. Figure 6 shows the estimated range of the Strain hardening exponent (n) based on the ISE of the two materials samples $(0.1 \%$ Carbon steel and mild steel). In the work, the ' $\alpha$ ' constant ranged between 0.3 to 0.4 , any value higher that 0.4 will result in a negative 'n' value, which is physically not possible. 


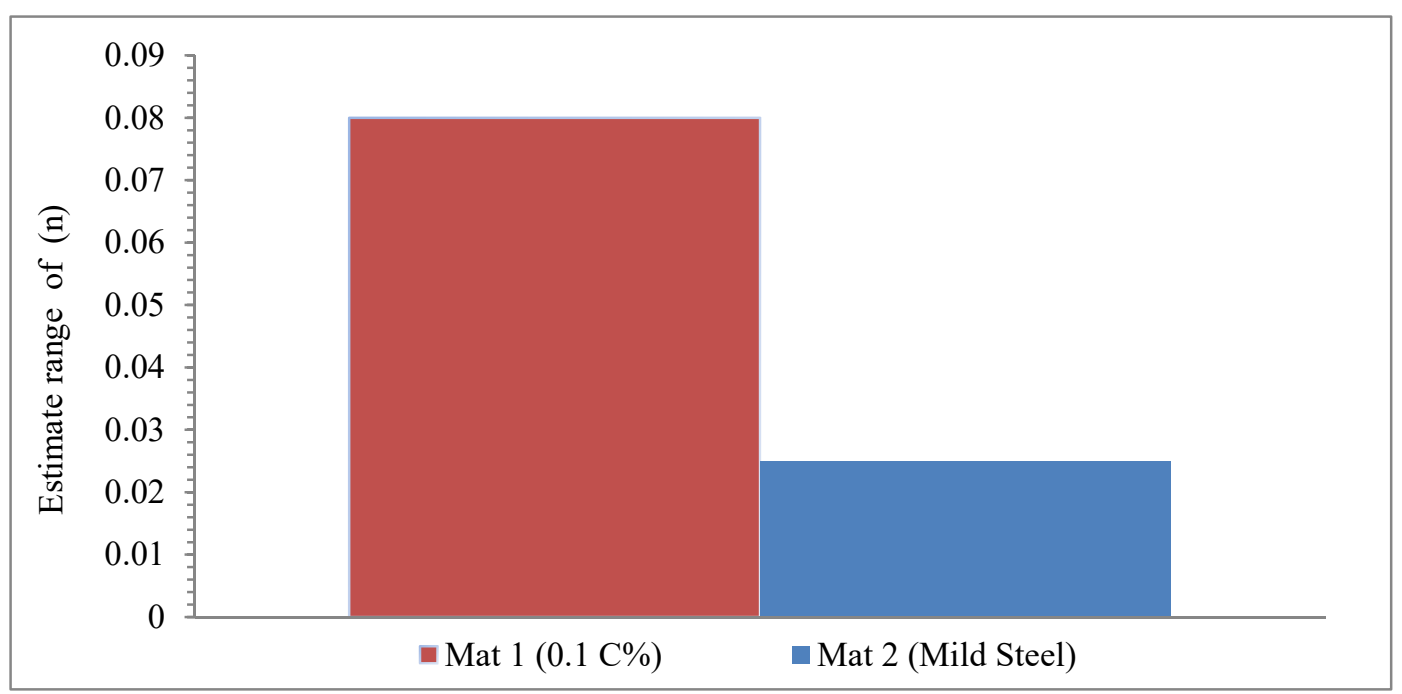

Figure 6 Estimated range of the Strain hardening exponent (n) based on the ISE of two materials tests $(0.10 \%$ Carbon steel and mild steel). The $\alpha$ constant in Eq. 6 is ranged between 0.30 to 0.40 , any value higher than 0.4 results in a negative ' $n$ ' value)

With this scope of ' $n$ ' values, the predicted materials can be limited to a much reasonable range, as represented in Figure 7 The yield stress for mild steel is seen as inside 500-600 MPa with $\mathrm{n}$ inside 0.08 . This is significantly more near the genuine estimated values. Further work is required to assess this idea and decide the precise incentive for $\alpha$ constant more robustly, which would then be able to additionally decrease scope of the Strain hardening exponent $(\mathrm{n})$ values and the yield stress.

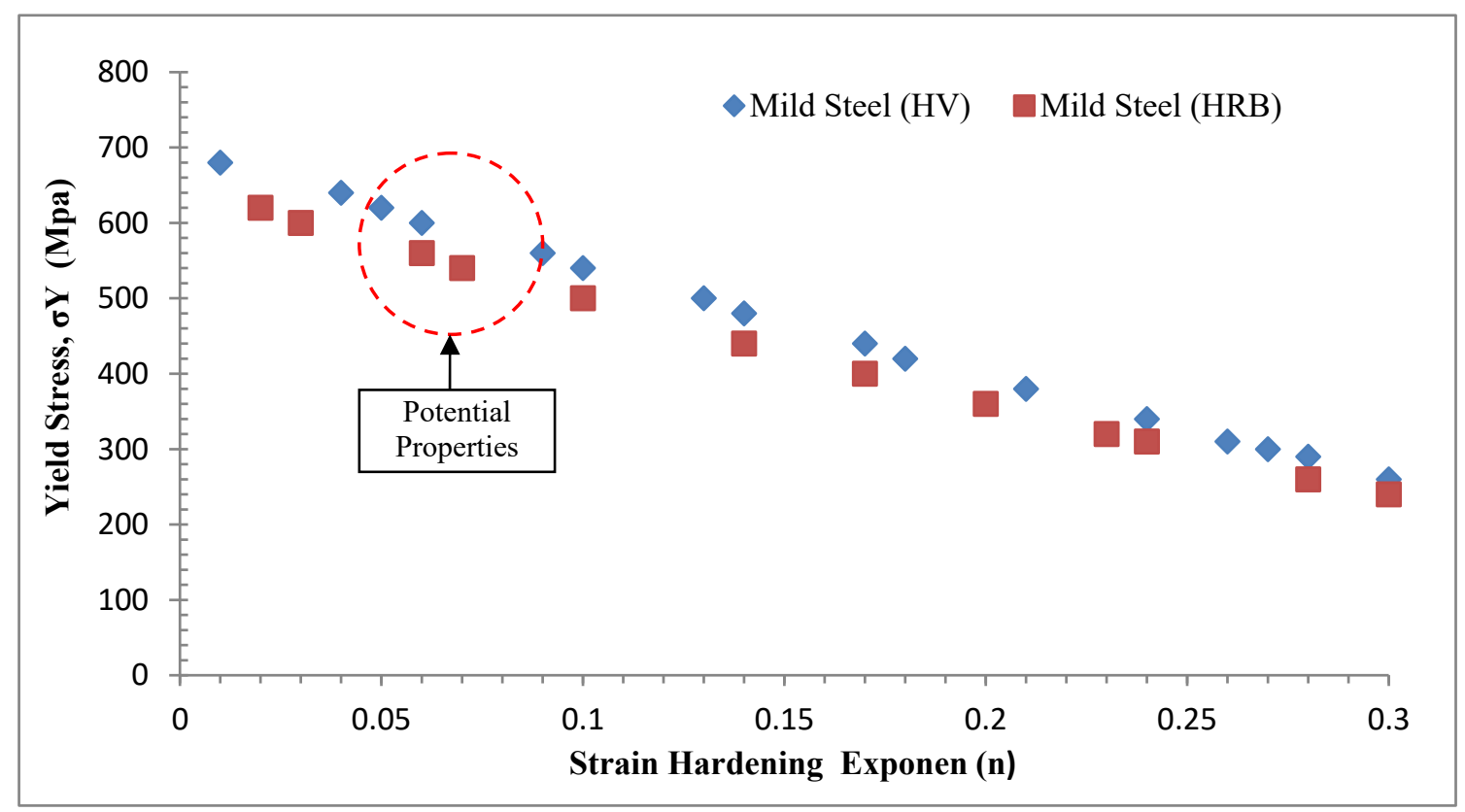

Figure 7 Properties prediction based on the range of the work hardening coefficients. Black diamond denote hardness value (HV) corresponding to yield stress for Mild Steel and Black squares denote hardness value (HRB) corresponding to yield stress for Mild Steel

\section{CONCLUSION.}

The evaluation of material properties by instrumented indentation Showed that the characteristic indentation response represented P-h curve. Under a set of simplifying hypotheses, analytical and numerical approaches proofed that it is possible to establish the driving material parameters governing each indentation. A new concept to use the indentation size data of the Vickers indentation has been explored to improve the accuracy/robustness of inverse properties modelling based on hardness. Systematic experimental work has been performed on steel samples of different carbon contents and heat-treatments. The ISE data was analysed by 
fitting data following the power law and proportional resistance model. In both cases, the results show that the ISE can be linked to the hardness-to-modulus ratio (H/E).

A new concept of using ISE data for estimating the work hardening coefficients (n) values of steel has been explored and shown reasonable results for narrowing the range of predicted material properties based on hardness values, thus improve the robustness of the inverse program. The estimated range of the work hardening coefficients based on the ISE of the two materials. the ' $\alpha$ ' constant ranged between 0.3 to 0.4 The yield stress for mild steel is found to be within 500-600 MPa with $\mathrm{n}$ within 0.08 .

\section{ACKNOWLEDGMENT.}

This work was supported by the Research Centre and Community Service for Prosperity (LPPM) Udayana University through PNBP. The authors would also like thank to all the parties who have helped and supported the implementation of the study from the beginning till the publication of this paper.

\section{REFERENCES}

[1] Wang W., Lu K., 2002, Nanoindentation measurement of hardness and modulus anisotropy in Ni3 Al single crystals, J. Mater. Res., Vol. 17, No. 9

[2] I N Budiarsa, I N G Antara and I M G Karohika, 2019, "Indentation Size Effect of the Vickers Indentation to Improve the Accuracy of Inverse Materials Properties Modelling Based on Hardness Value”, IOP Conf. Ser.: Earth Environ. Sci. 248012009

[3] Ebisu, T., Horibe, S., 2010, Analysis of the indentation size effect in brittle materials from nannoindentation load-displacement curve. Journal of the European Ceramics Society 30, 2419-2426.

[4] Stegall D. E., Mamun A. M., Crawford B., Elmustafa A., 2012, Indentation size effect in FCC metals: An examination of experimental techniques and the bilinear behavior, J. Mater. Res., Vol. 27, No. 12,

[5] Li H., Bradt, R. C. 1992. The Microhardness Indentation Size-Load Effect (ISE) in Hard Ceramic Materials. J. Hard Mat. 3 (3-4), 403-419..

[6] G.D. Quinn, Patrice Green, and Kang Xu, 2003, "Cracking and the Indentation Size Effect for Knoop Hardness of Glasses,"J. Am. Ceram. Soc., 86 [3] 441-448.

[7] Han C. S., Nikolov S., 2007, Indentation size effects in polymers and related rotation gradients, J. Mater. Res., Vol. 22 , No. 6.

[8] Sangwal K., 2000, On the reverse indentation size effect and microhardness measurement of solids, Materials Chemistry and Physics, $63,145-152$

[9] Ma, Q., Clarke, D.R., 1995. Size dependent hardness of silver single crystals. Materials research Society $10,853$.

[10] Zong, Z., Lou, J., Adewoye, O. O., Elmustafa, A. A, Hammad, F., Soboyejo, W. O., 2006. Indentation size effect in the nanno-and micro-hardness of fcc single crystal metals. Materials Science and Engineering A 434, 178-187.

[11] Huang, Y., Qu, S., Hwang, K.C., Li, M., Gao, H., 2004, A conventional theory of mechanism-based strain gradient plasticity. International Journal of Plasticity 20, 753-782.

[12] Han, C., Gao, H., Huang Y., Nix,W.D., 2005. Mechanism-based strain gradient crystal plasticity-I. Theory. Journal of the Mechanics and Physics of solids 53, 1188-1203

[13] Gao, H., Huang, Y., Nix, W.D., Hutchinson, J.W., 1999.Mechanism-based strain gradient plasticity-I Theory. Journal of the Mechanics and Physics of Solids 47, 1239-1263.

[14] Brooks, C.A., 1981. In "Science of Hard Materials, Jackson, Wyoming", edited by Viswamnadham, R. K., Rowcliffe, D. J.,and Gurlan, J., (Plenum Pres, New York,1983) p.181

[15] I N Budiarsa, I N G Antara, I M Astika, I W Widhiada, Determining Plastic Properties Of Material Through Instrumented Indentation Approach, International Journal of Advanced Research in Engineering and Technology (IJARET), Vol.10,1, (2019), p 249-257

[16] Bolzon G., Maier G. and Panico M., 2004, Material model calibration by indentation, imprint mapping and inverse analysis, Inter. Journal of Solids and Structures, Vol. 41, pp. 2957-2975.

[17] I Nyoman Budiarsa, I D.G Ary Subagia, I Wayan Widiada, Ngakan P.G Suardana, Characterization of Materials Parameters by Reverse Finite Element Modelling Based on Dual Indenters Vickers and Spherical Indentation, Procedia Manufacturing, 2, 2015, p $124-129$

[18] Nix W. D., Gao H., 1998, Indentation size effects in crystalline materials: a law for strain gradient plasticity. J Mech. Phys. Solids 46, pp. $411-425$.

[19] Dao M., Chollacoop N., Van Vliet K. J., Venkatesh T. A. and Suresh S., 2001, Computational modelling of the forward and reverse problems in instrumented sharp indentation, Acta Materialia, Vol. 49, pp. 3899-3918.

[20] Kim J. Y., Kang S. K., Greer J. R., Kwon D., 2008, Evaluating plastic flow properties by characterizing indentation size effect using a sharp indenter, Acta Materialia 56, 3338-3343

\section{Author Profile}

I Nyoman Budiarsa, is an associate Professor of Mechanical engineering Materials in the Dept.Mechanical Engineering Udayana University. Bali Indonesia. Completing Ph.D at Liverpool John Moores University. UK in the field Mechanical Materials and until now active in research, especially in Finite Element Modeling, Materials characterization and simulated based on instrumented indentation, Surface effects in solid mechanics models \& simulations, and Surface mechanics. Active participation in the Scientific Committee and as editor for several International conferences until now active in teaching and in the organization or association in their fields.

I Nyoman Gde Antara, Completing M.Sc degree in Mechanical Design and Production Engineering and Received Doctor Degree in Materials science from Nagaoka University of Technology Japan. Currently, he serves as a Full Professor in the field of Material Engineering at Department of Mechanical Engineering, faculty of Engineering Udayana University, Bali, Indonesia. As a member on Japan Institute of metal and active participation in the Scientific Committee, editor being a reviewer and keynote speakers for several International conferences. His research interest covering subjects such as, material characteristic biomaterial, nano materials, metallurgy, Semi- Solid Forming and Light Metal 